\title{
Epidemiological Status of Bovine Theileriosis in Uttar Pradesh a state of India
}

\author{
Kumar $\mathrm{S}^{1 *}$, Mohmad A1, Parthasarathi BC1, Fular $\mathrm{A}^{1}$, Gupta $\mathrm{S}^{2}$ and \\ Singh $\mathrm{D}^{3}$ \\ ${ }^{1}$ Division of Parasitology, ICAR-Indian Veterinary Research Institute, India \\ ${ }^{2}$ Department of Veterinary Parasitology, Lala Lajpat Rai University of Veterinary and \\ Animal Sciences, India \\ ${ }^{3}$ Deparment of Geography, Bhagirathi degree college, India
}

\section{Case Report}

Volume 2 Issue 1

Received Date: December 20, 2017

Published Date: January 24, 2018

DOI: $10.23880 /$ mjccs-16000130

*Corresponding author: Sachin Kumar, Division of Parasitology, ICAR-Indian Veterinary Research Institute, Izatnagar 243122, UP, India, E-mail: sachin.amroha@gmail.com

\section{Abstract}

Tropical theileriosis has long been recognized as a hindrance to the development of sound dairy industry in the India and is a cause of major economic losses. Serological surveys indicated that Theileria annulata infection is widespread in the country but the disease mostly affects exotic dairy breeds and their crosses with indigenous breeds. The prevalence of Theileria infection in tick vector Hyalomma anatolicum collected from healthy animals of Sub-humid regions of India. Theileria caused by Theileria annulata is economically important vector borne haemoprotozoan disease of livestock. Theileria is responsible for causing theileriosis resulting in death of affected animals. The disease is endemic in warmer regions, it is seasonal and the incidence is higher during summer and rainy season when the ticks have higher activity although sporadic outbreaks have been recorded year round. It is a potential killer of livestock and causes economic losses in terms of mortality, morbidity, abortion, infertility, reduced milk yield etc. The disease is underestimated in cattle due to sub clinical nature. The conventional parasitological techniques are less sensitive. More than 80 percent of infections are cryptic and undetectable by direct microscopy. This paper briefly discuss about the occurrence, control and the economic importance of Theileria spp. in Western Himalayan region of Uttar Pradesh.

Keywords: Hyalomma anatolicum; Theileria annulata; PCR; Theileriosis; Livestock

Abbreviations: TBD: Tick-Borne Diseases; IFAT: Immunoflourescent Antibody Test; PCR: Polymerase Chain Reaction; LAMP: Loop Mediated Isothermal Amplification.

\section{Introduction}

Ticks and tick-borne diseases (TBDs) cause major economic losses, and affect many domestic animals, 


\section{Medical Journal of Clinical Trials \& Case Studies}

mainly cattle and sheep, in tropical and subtropical regions. Tropical theileriosis is a TBD caused by a protozoon called Theileria annulata transmitted by several tick species of the genus Hyalomma [1]. Theileriosis and babesiosisare the most important and dangerous blood protozoan diseases of the cattle, these are transmitted by ticks especially in countries which have intensive animal industries [2]. Tropical theileriosis is a frequent fatal disease of cattle caused by the protozoan parasite Theileria annulata.

The temperature of Uttar Pradesh region is favorable for ticks and responsible for the transmission of theileriosis in cattle. It is situated on the northern spout of India and shares an international boundary with Nepal. The Himalayas border the state on the north, but the plains that cover most of the state are distinctly different from those high mountains. Cattle are the important species in these areas because of dual purpose. They are reared for the supply of draught power for agriculture and for milk production.

This is because of the introduction of new cattle from the surrounding states where this disease is prevalent. Uttar Pradesh has a humid subtropical climate and experiences four seasons. The Gangetic plain varies from semiarid to sub-humid. The mean annual rainfall ranges from $650 \mathrm{~mm}$ in the southwest corner of the state to 1000 $\mathrm{mm}$ in the eastern and southeastern parts of the state. The winter in January and February is followed by summer between March and May and the monsoon season between June and September. Summers are extreme with temperatures fluctuating anywhere between $0^{\circ} \mathrm{C}$ and $50^{\circ} \mathrm{C}$ in parts of the state coupled with dry hot winds called the Loo.

The present paper attempts to present a scenario of theileriosis, their occurrence in Uttar Pradesh, reason of occurrence, effects and their preventive measures. So that dairy venture become more profitable and mortality rate in crossbred cattle due to theileriosis should be reduced.

\section{Theileriosis}

The Theileria parasite was first reported by Arnald Theiler and Dschunkowsky first described the disease theileriosis in 1904. Theileriosis is caused by Theileria annulata and transmitted through the bites of Hyalomma and Rhipicephalus with higher incidence in the crossbred cow of all age groups with the general epidemiology of the disease in tropical areas [3]. This disease is seasonal, starts in the second part of April, and adds to its abundance increase in June and July. Cases of theileriosis are generally observed during summer or rainy season when the ticks have higher activity although sporadic outbreaks have been recorded year round [4]. Tropical theileriosis caused by T. annulata may result in $80 \%$ mortality in susceptible animals.

Acute clinical cases of theileriosis were first recorded on 12 June, 1922 in hill bulls. In 1930 outbreak of clinical theileriosis were recorded in imported herds maintained at Lahore, Bangalore, Allahabad and Kirkee. Since then occasional outbreaks of theileriosis have been recorded mainly in cross bred and exotic cattle.

Treated cattle turn out to be long standing carriers, with only a few numbers of infested erythrocytes, thus posing difficulty in the demonstration of parasites in blood smear. In long standing carrier animals blood smears are negative on microscopy [5]. Carrier animals have an important role in the transmission of infection by the Hylomma ticks. Antibodies tend to disappear in long term carrier cattle despite the presence of piroplasms [6]. Transport of carrier cattle to non endemic areas can lead to disease outbreak. It is possible for cattle infected with these parasites to maintain carrier state for several years.

Piroplasms are very small $<2.5 \mathrm{~m}$ they are ovoid, annular, ring or rod shaped. Radostits et al., Roy et al. found highest prevalence in monsoon months. Minjauw and Mcleod (2000) have estimated the cost of T.annulata in India to be US\$ 384.3 million. A recent estimate of US\$ 498.7 million per annum has been calculated as the cost of TTBD's in India.

\section{Pathogenesis}

The life cycle of T. annulata includes the following stages: Sporozoite Stage: When infected adult ticks attach to cattle, the sporozoites develop in the tick salivary gland and are injected with the tick saliva. The sporozoites invade the lymphoid cells and schizonts are detected in 10-13 days. This is the prepatent period of the disease.

Schizont Stage: The schizonts parasitize lymphocytes, proliferate and invade and damage the lymphoid system and produce lesions in the skin, liver and spleen.

Piroplasm Stage: The piroplasm parasitizes the erythrocytes and causes destruction of these cells with a decrease in the erythrocyte count and haemoglobin level.

Symptoms: Clinically a rise of body temperature up to $107^{\circ} \mathrm{F}$ and enlarged superficial lymph nodes accompanied by dullness, anorexia, salivation, lacrimation, discharge from nostrils, tachycardia, decreased milk production are the symptoms for theileria (El-Deeb Younis, 2009). 


\section{Medical Journal of Clinical Trials \& Case Studies}

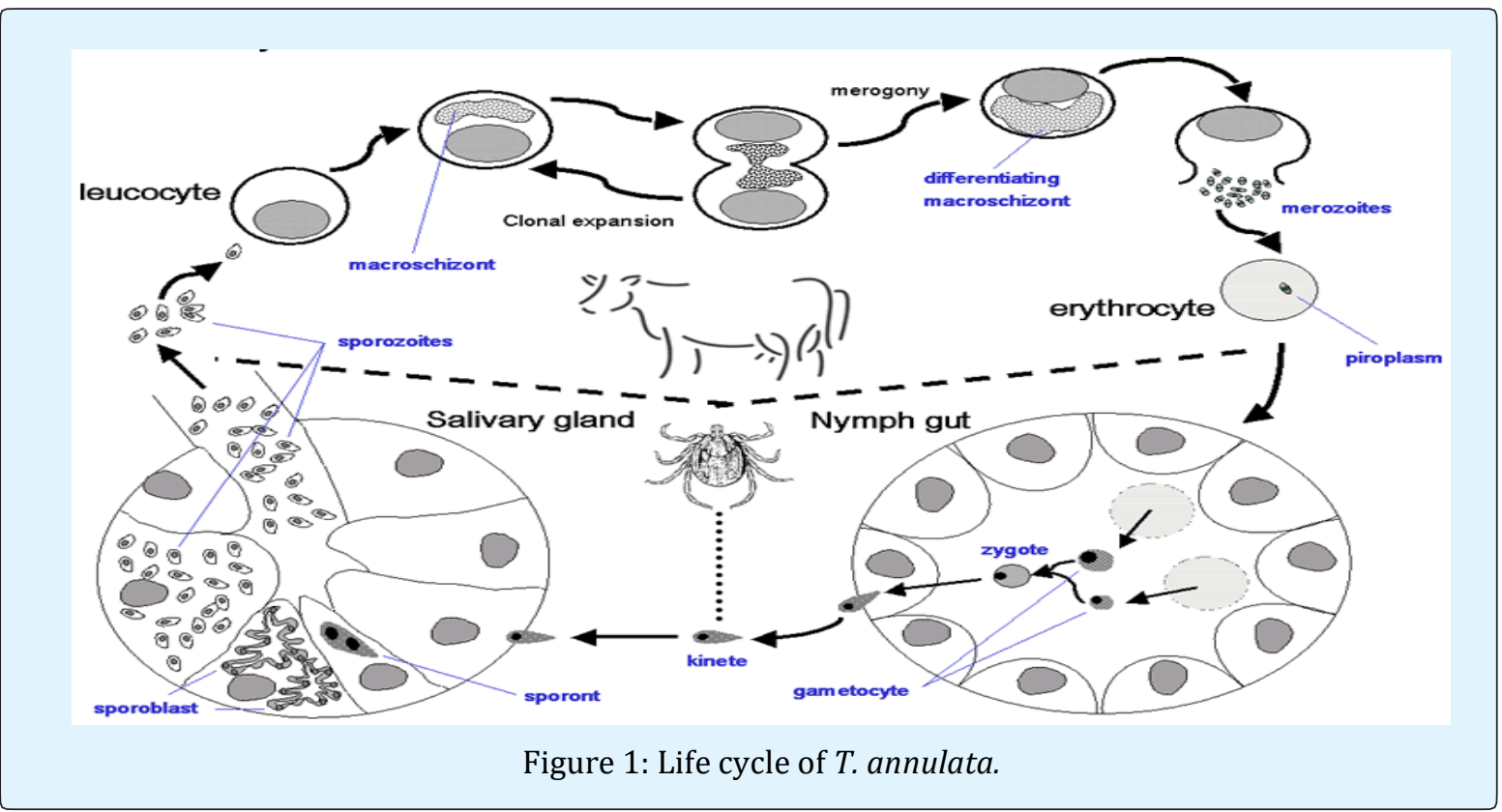

\section{Diagnosis of Theileriosis}

\section{Microscopic Examination}

Theileria annulata infection in cattle is usually based on the detection of macroschizonts in Giemsa's-stained lymph node biopsy smears in live animals and impression smears of lymph node and spleen in dead animals [5].

\section{Serological Examination}

Serological tests such as the indirect immunoflourescent antibody test (IFAT) can be used to detect circulating antibodies [7,8]. However, crossreactivity with antibodies directed against other Theileria species limits the specificity of the IFAT [6].

\section{DNA Based Examination (PCR \& LAMP)}

PCR: Molecular diagnosis of haemoprotozoan diseases involves several PCR- based diagnosis procedures, which help in the identification of the parasites up to the species or even strain level [9-12]. With the availability of sequenced parasite genes and PCR, it is possible to detect parasites within samples of blood. PCR based technique uses small material which is very relevant because large amount of material is not possible from different stages of parasitic life cycle [13]. This technique reveals a high sensitivity compared to immunological examinations and serological testing. Furthermore, the advent of the polymerase chain reaction (PCR) technique has made it possible to increase the sensitivity of nuclear hybridization techniques, through amplification of target DNA sequences of the parasites in test material, by in situ synthesis of these sequences prior to hybridization with the diagnostic probe. Despite the benefits of PCR based technologies, such as high specificity and sensitivity to detect some parasites the main disadvantage of these methods is that they are very time consuming and do not provide quantitative data [14].

Loop Mediated Isothermal Amplification (LAMP): It is sensitive and specific and less time consuming method [15]. It is characterized by use of DNA polymerase that has low sensitivity to inhibitors and the set of four primers to recognize six different sequences on target gene [16]. It can amplify 109 copies in an hour [17]. It is isothermal technique which uses water bath. It has been used for Babesia and Theileria [16,18-20]. It can be used without DNA extraction [21].

\section{Treatment}

There are three effective drugs available for the treatment of Theileriosis namely; parvaquone, buparvaquone, and halofuginone lactate are used worldwide [22]. Research work regarding the efficacy of these drugs has shown that buparvaquone, secondgeneration hydroxynaphthoquinone, is more effective so far. Early treatment with buparvaquone was $100 \%$ effective in eliminating the protozoan parasites from the blood and lymph nodes and led to an improvement in the clinical state whereas treatment in the later stages of the disease whilst eliminating the parasites failed to improve the clinical condition of the animal [23]. 


\section{Medical Journal of Clinical Trials \& Case Studies}

\section{Status of Theileriosis in India}

India being one of the 12 mega biodiversity country contribute significantly to world flora and fauna. As a result India with its tropical climate is hub of several vector borne diseases like bovine tropical theileriosis. $T$. annulata, the causative agent of tropical thcileriosis has a much wider distribution; it is found in Southern Europe, Northern Africa, and Egypt to the Sudan, the Middle East, India, parts of the former Soviet Union and southern China. T.annulata, originating from Asian water buffalo (Bulbulus bubulis), and transmitted by several Hyalomma tick species, is responsible for tropical theileriosis from Southern Europe to China, a vast region in which an estimated 250 million cattle are at risk. Livestock plays a critical role in the welfare of India. Indigenous cattle are resistant to this disease but cross bred cattle are highly sensitive to theileria [24]. The theileria parasites have detrimental effect on the cows as it causes high mortality in the animals and there is an irreversible loss of production and reproduction. Theileria and Babesia both have same symptoms like high fever and both are fatal diseases, but in babesia blood comes out with the urine and hence it is also known as Red water disease. Medicine for babesia is easily available but for theileria it is not easily available as it is very costly. So smallholder dairy farmers would prefer to run the risk of tropical theileriosis rather then they pay for the vaccines.

Serological surveys conducted indicated that 30-60\% of cross bred cattle were positive for antibodies to $T$. annulata piroplasms, all over India, except in Himalayan regions, where climate is not favorable for tick activity. In India theileriosis has been reported from Punjab, Haryana, Gujarat etc. geographical regions. Anand et al. reported the occurrence of T. Annulata among crossbred cattle in Bangalore north. Nair et al. reported $16 \%$ positive cases of theileriosis in crossbred cattle of Northern Kerala [24]. Vahora, et al. reported 37\% cattle found positive for the haemoprotozoan infection in Kaira and Anand District of Gujrat. Samanta and Dutta also reported a case of tropical theileriosis from West Bengal. Mahajan, et al. has reported the outbreaks of theileriosis in cattle of Punjab with $4.86 \%$ mortality rate.

If animals suffering from tropical theileriosis are treated with antiparasitic drugs, T. annulata is removed from lymph nodes and remains in blood at very low numbers and these animals becomes the carrier of parasites. In carrier animals blood smears are negative on microscopy [5]. Carrier animals have an important role in the transmission of infection by the Hyalomma ticks. Negative microscopic examination does not exclude the possibility of infection.

\section{Status of Theileriosis in Uttar Pradesh}

Livestock are the important part of the rural population. Uttar Pradesh is specialized in smallholder dairy production system. Cattle have been the important species in the herd. Due to moderate climate of the region, ticks responsible for the blood-borne diseases are not in the active form or found less. No earlier case of theileriosis is reported from the region. But to increase the milk production rate, cross bred cattle have been introduced in the Uttar Pradesh state from the neighboring states like Haryana, Punjab, and Rajasthan etc where these diseases are prominent and many of these animals may be the carriers. These animals are the source of infection. Infection is usually caused by tick that migrates from carrier animals to non infected animals. Now some cases found positive for theileriosis in a preliminary survey. The reason for the occurrence of theileriosis is the introduction of carrier cattle to the herd of healthy animals. The stress due to extreme of climate may be the contributory factor.

Infection by theileria limits the movement of cattle between the countries and can result in the production losses and high mortality in susceptible animals. Due to lack of sensitive diagnostic methods and lack of cost effective treatment for the detection of clinical cases and carrier animal majority of cattle positive for theileria are left untreated.

Present status of the animal diseases needs a serious attention in terms of research. Minjauw and Mcleod have estimated the cost of T. annulata in India to be $\$ 384.3$ million. Vaccination against this disease is not practiced due to higher cost and non-availability. To reduce the chance of introducing the parasite first is essential screening should be done before introduction of the cross bred cows to the areas where the chance of occurrence of such disease is very low or introduced from the districts where infection is uncommon. The second is treat the cattle for ticks on arrival and don't mix them with home cattle. So the aim is monitoring cattle for the blood protozoan through microscopic examination and by using Polymerase Chain Reaction (PCR). PCR monitors the presence of parasites which are not visible by microscopic examination and in the preclinical cases.

\section{Effect on Milk Production}

Theileria annulata infection was diagnosed as the cause of severely depressed milk yields in Friesian cows [25]. It was also found that cows of higher producing breeds were generally susceptive to the tick and the effect on milk production appeared to be greater [26]. 


\section{Medical Journal of Clinical Trials \& Case Studies}

\section{Effect on Reproduction}

Previous studies confirmed that theileriosis has an adverse effect on reproduction. Pregnant animals introduced to endemic bush tick areas are especially at risk and should be monitored carefully after introduction for signs of theileriosis [27].

\section{Effect on Thyroid Hormone}

A number of experimental conditions have been used to evaluate hormonal secretion during heat stress including short-term temperature modification using environmental chamber, seasonal comparisons of hormonal-profiles and the use of micro climatic modification during period of heat stress. Johnson and Vanjonack stated that the thyroid function in the lactating animals showed a general depression in the summer months and was normal or elevated during winter months [28].

It was also reported that thyroid hormones are affected in cases of tropical theileriosis caused by Theileria annulata [29-31]. It is stated that thyroid hormones, which affect growth, development, energy and efficiency metabolisms necessary for the development and normal functioning of many cells, are closely associated with the regulation of oxygen consumption [32-35]. Sangwan et al. and Garg et al. reported that thyroid hormones decrease in tropical theileriosis [30,31].

\section{Conclusion}

A future strategy of dual vaccination with tick antigen and associated recombinant T.annulata antigen can aid to achieve integrated protection in host.

Conflicts of interest: There are no conflicts of interest

\section{Acknowledgment}

The authors are grateful to the Department of Science and Technology, New Delhi for funding through the Science and Engineering Research Board Project.

\section{References}

1. Robinson PM (1982) Theileriosis annulata and its transmission-a review. Trop Anim Health Prod 14(1): 3-12.

2. Balha T (1989) Applied Veterinary Epidemiology. $1^{\text {st }}$ (Edn.), Elsevier Science Publishers, Sara Burgerhartstraat 25, Netherland.
3. Jithendran KP (1997) Blood protista of cattle and buffaloes in Kangra valley, Himachal Pradesh. Indian J Anim Sci 67(3): 207-208.

4. Meenakshisundaram A, Anna T, Malmarugan S (2014) Concomitant theileria annulata and anaplasma marginale infections in a cross bred dairy herd. Ind J Vet \& Anim Sci Res 43(6): 422-425.

5. Aktas M, Dumani N, Etinkaya B, Ahmad A (2002) Field evaluation of PCR in detecting Theileria annulata infections in cattle in the east of Turkey. Vet Rec 150(17): 548-549.

6. Burridges MJ, Brown CGD, Kimber CD (1994) Theileria annulata: cross reaction between a cell culture schizont antigen and antigen of east African Theileria species in the indirect fluorescent antibody test. Experimental Parasitol 35(3): 374-380.

7. Pipano E, Shkap V (2000) Vaccination against tropical theileriosis. Ann N Y Acad Sci 916: 484-500.

8. Musoke AJ, Morzaria SP, Nkonge C, Jones E, Nene V (2001) A recombinant sporozoit surface antigen of Theileria parva induced protection in cattle. Proc Nat Acad Sci 89(2): 514-519.

9. Figueroa JV, Chieves LP, Johnson GS, Buening GM (1993) Multiplex polymerase chain reaction based assay for the detection of Babesiabigemina, Babesia bovis, and Anaplasma marginale DNA in bovine blood. Vet Parasitol 50(1-2): 69-81.

10. Birkenheurer A, franco JR, Simarro PP, Stich A, Abel PM (2003) Development and evaluation of a seminested PCR for detection and differentiation of Babesia gibsoni (Asian genotype) and B. Canis DNA in canine blood samples. J of Clinical Microbio 41(9): 4172-4177.

11. Rampersad J, Cesar E, Campbell MD, Samlal M, Ammons D (2003) A field evaluation of PCR for the routine detection of Babesia equi in horses. Veterinary Parasitology 114(2): 81-87.

12. Criado- Fornelio A, Martinrz- Marcos A, Buling Sarana A, Barba- Carretero J (2003) Molecular studies on Babesia, Theileria an Hepatozoon in Southern Europe. Part I Epizootiological aspects. Vet Parasitol 113(34): 189-201.

13. Gasser RB (2006) Gasser RB. Molecular tools advances, opportunities and prospects. Vet Parasitol 136(2): 69-89. 


\section{Medical Journal of Clinical Trials \& Case Studies}

14. Lin MH, Chen TC, Kuo TT, Tseng CC, Tseng CP (2000) Real-time PCR for quantitative detection of Toxoplasma gondii. J Clin Microbiol 38(11): 41214125 .

15. Parida M, Sannarangaiah S, Dash PK, Rao PV, Morita K (2008) Loop mediated isothermal amplification (LAMP): a new generation of innovative gene amplification technique; perspectives in clinical diagnosis of infectious diseases. Rev Med Virol 18(6): 407-421.

16. Paris DH, Imwong M, Faiz AM, Hasan M, Yunus EB, et al. (2007) Loop-mediated isothermal PCR (LAMP) for the diagnosis of falciparum malaria. Am J Trop Med Hyg 77(5): 972-976.

17. Notomi T, Okayama $H$, Masubuchi $H$, Yonekawa $T$, Watanabe K, et al. (2000) Loop-mediated isothermal amplification of DNA. Nucleic Acids Res 28(12): E63.

18. Nkouawa A, Sako Y, Nakao M, Nakaya K, Ito A (2009) Loop-mediated isothermal amplification method for differentiation and rapid detection of Taenia species. J Clin Microbiol 47(1): 168-174.

19. Bakheit MA, Torra D, Palomino LA, Thekisoe OM, Mbati PA, et al. (2008) Sensitive and specific detection of Cryptosporidium species in PCR-negative samples by loop-mediated isothermal DNA amplification and confirmation of generated LAMP products by sequencing. Vet Parasitol 158(1-2): 1122.

20. Iseki $\mathrm{H}$, Alhassan $\mathrm{A}$, Ohta $\mathrm{N}$, Thekisoe OM, Yokoyama $\mathrm{N}$, et al. (2007) Development of a multiplex loopmediated isothermal amplification (mLAMP) method for the simultaneous detection of bovine Babesia parasites. J Microbiol Methods 71(3): 281-287.

21. Njiru ZK, Mikosza ASJ, Matovu E, Enyaru JCK, Ouma J0, et al. (2008) African trypanosomiasis: sensitive and rapid detection of the sub-genus Trypanozoon by loop-mediated isothermal amplification (LAMP) of parasite DNA. Int J Parasitol 38(5): 589-599.

22. Ngumi PN, Lesan AC, Williamson SM, Awich JR (1994) Isolation and preliminary characterization of a previously unidentified Theileria parasite of cattle in Kenya. Res Vet Sci 1(57): 1-9.

23. Salama AO, Gaabarya MHA (2007) Clinical, haematological and therapeutic studies on tropical theileriosis in water buffaloes (Bubalus bubalis) in Egypt. Vet Parasitol 146(3-4): 337-340.
24. Nair AS, Ravindran R, Lakshmanan B, Kumar SS, Tresamol PV, et al. (2011) Haemoprotozoan of cattle in Northern Kerala, India. Trop Biomed 28 (1): 68-75.

25. Michael SA, el Refaii AH, McHardy N, Rae DG (1989) Effect of treatment of chronic theileriosis with buparvaquone on milk yields. Trop Anim Health Prod 21(4): 218-222.

26. Norval RAI, Lawrence JA, Young AS, Perry BD, Dolar TT, et al. (1991) Theileria parva: influence of vector, parasite and host relationships on the epidemiology of theileriosis in southern Africa. Parasitology 102: 347-356.

27. Rumberia RM, Eley RM, Young AS, Rowland AC, Watson ED (1993) The effect of high and low dose Theileria parva infection on the reproductive function of Boran/Friesian heifers. Theriogenology 40(5): 977-986.

28. Johnson HD, Vanjonack WJ (1976) Effects of environmental and other stressors on blood hormone patterns in lactating animals. Journal of Dairy Science 59(9): 1603-1617.

29. Badiei K, Jaber M (2002) Changes of hormones (T3, T4 and Cortisol) in Theileria annulata infected cattle. Proceedings of the 22th World Buiatrics Congress, Germany, pp: 346-359.

30. Garg SL, Rose MK, Agarwali VK (2001) Plasma cortisol and thyroid hormone concentration in cross bred cow calves affected with theleriosis. Indian Vet J 78: 583-585.

31. Sangwan N, Sangwan AK, Singh S, Agarwal VK (2002) Cortisol and thyroid hormones in relation to bovine tropical theileriosis. Indian J Anim Sci 72(12): 10981099.

32. Guyton AC (1986) Textbook of medical physiology. $7^{\text {th }}$ (Edn.), WB Saunders Company, Philadelphia, USA.

33. Sanli Y (1999) Veterianary Clinic Pharmacology and Medicine Therapy Principles. 3rd (Edn.), Ozkan Matbaacilik Ltd., Ankara.

34. Turgut K (2000) Veterinary Clinic laboratory Diagnosis. 2 ${ }^{\text {nd }}$ (Edn.), Printer Gardeners, Konya.

35. Sawhney RC, Malhotra AS (1990) Thyroid function during intermittent exposure to hypobaric hypoxia. Int J Biometeoral 34(3): 161-163.

36. Cytauxzoonoses: a review. Onderstepoort J Vet Res. 


\section{Medical Journal of Clinical Trials \& Case Studies}

37. Government of Uttar Pradesh, Lucknow, Irrigation Department Uttar Pradesh (2012) Average rainfall pattern of Uttar Pradesh.

38. Moorhouse PDS, Musisi FL, Mwase ET, Snacken M (2001) The epidemiology of bovine theileriosis in Zambia: results of a longitudinal study in Southern Province. In: Proceedings of the $4^{\text {th }}$ International Symposium on Veterinary Epidemiology and Economics. Singapore: Singapore Veterinary Association 389-391.
39. Neitz WO (1957) Theileriosis, gonderioses and cytauxzoonoses: a review. Onderstepoort J Vet Res 27(3): 275-430.

40. Tait A, Hall FR (1990) Theileria annulata: control measures, diagnosis and the potential use of subunit vaccines. Rev Sci Technol 9(2): 387-403.

41. Prakashan U (2008) Uttar Pradesh General Knowledge. Upkar Prakashan, pp: 26 